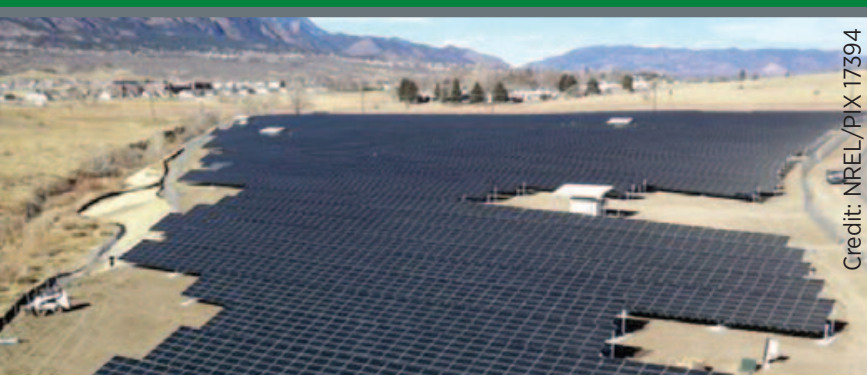

The U.S. Department of Energy's (DOE) Federal Energy

Management Program (FEMP) facilitates the Federal

Government's implementation of sound, cost-effective energy

management and investment practices to enhance the nation's

energy security and environmental stewardship.

Fort Carson's 2 MW solar array is one of the renewable technologies

being used at DOD installations in the Rocky Mountain region to

provide local clean energy to meet base energy needs.

\title{
FEMP TECHNICAL ASSISTANCE TO U.S. NORTHCOM
}

With support from FEMP, three DOE laboratories are providing integrated technical assistance to DOD's U.S. Northern Command (NORTHCOM) to increase energy security at eight Rocky Mountain installations through energy efficiency, renewable energy and secure microgrids.

The U.S. Department of Defense (DOD) has long recognized the strategic importance of energy to its mission, and is working to reduce energy consumption and to enhance energy security by drawing on local clean energy sources. Through FEMP, NORTHCOM has partnered with DOE National Laboratories to assess opportunities for increasing energy security through energy efficiency, renewable energy, microgrids, and a regional smart grid at eight Front Range installations:

- United States Air Force Academy

- F.E. Warren Air Force Base

- Fort Carson

- Buckley Air Force Base

- Cheyenne Mountain

- Peterson Air Force Base

- Schriever Air Force Base

- Pueblo Chemical Depot

FEMP has funded $\$ 700,000$ to three labs - National Renewable Energy Laboratory (NREL), Sandia National Laboratory (SNL), and Pacific Northwest National Laboratory (PNNL) for initial feasibility assessments of the project.

\section{Task 1: Regional Smart Grid Assessment}

PNNL assessed the technical, legal, and regulatory feasibility of a regional smart grid. Under this concept, the eight Front Range installations would be electrically connected, and renewable power generated onsite at one installation could be shared with other installations. The resulting integrated system would provide a secure source of energy for critical mission needs, including support of other bases and off-base critical loads during major energy outages. PNNL found that the renewable resource potential exists, and the regional grid is in place to facilitate wheeling power between bases and directing power to DOD critical loads. At this time, however, the concept is not practical. Costs are likely to be prohibitive. Decentralized solutions relying on generation at each base are lower in cost, and do not require grid modification. Based on these findings, the remaining tasks focus on strategies for increasing energy security at individual bases.

\section{Task 2: Renewable Energy Assessments}

NREL completed high-level renewable energy assessments of the eight Rocky Mountain installations to evaluate opportunities for renewable energy development. NREL's Renewable Energy Optimization (REO) tool was used to determine the most cost-effective combination of energy technologies at each installation. Results indicate use of solar ventilation preheating, solar water heating, ground source heat pumps, and wind energy would reduce the overall 25 -year life-cycle cost of energy compared to the current fossil-based utility energy baseline. To further reduce dependence on fossil fuels and achieve net-zero energy, additional technologies including photovoltaics, concentrating solar power, and daylighting should also be included. Payback periods for the minimum life-cycle cost solutions at each installation range from 7 to 23 years, while paybacks for the net zero solutions range from 39 to 79 years.

After the initial renewable assessments were completed for all eight installations, more detailed analysis was completed for one installation, Fort Carson. 


\section{Task 3: Fort Carson Detailed Energy Assessment}

The Fort Carson detailed energy assessment includes three components: 1) Net zero energy installation assessment; 2) Electric Vehicle Grid Integration Study; and 3) Secure Microgrid Design.

\subsection{Net Zero Energy Installation Assessment}

This assessment examined the potential for Fort Carson to produce as much energy on site from renewable energy generation, as they consume in buildings, facilities, and fleet vehicles. The assessment began with a baseline of current electrical, thermal, and transport fleet energy consumption. Energy conservation and efficiency projects were explored to identify economic approaches to minimizing energy demand. Renewable energy generation technologies were then examined for their potential to meet the remaining energy loads, and fleet fuel use was analyzed for opportunities to switch to alternative fuels or electric vehicles. This assessment provides recommendations for efficiency, renewable, and transportation energy projects at Fort Carson that reduce reliance on fossil fuels and increase energy security.

\subsection{Electric Vehicle Grid Integration Study}

NREL evaluated opportunities for using electric vehicles to reduce fuel use and provide energy storage for renewables. The results of this study show how electric vehicles can be used to store energy in times of high renewable generation and supply energy during low renewable generation periods, helping to balance load and energy generation requirements.

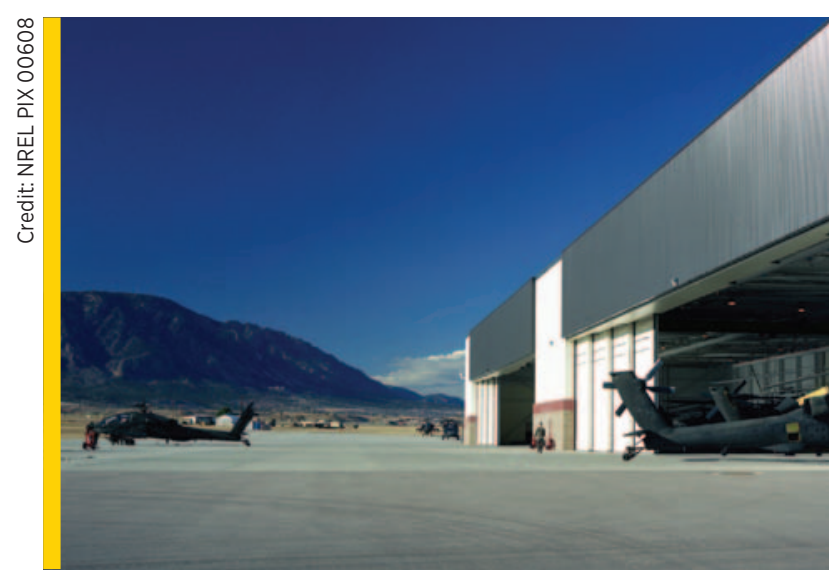

Solar ventilation preheating system (solar wall) installed on a Fort Carson vehicle maintenance building

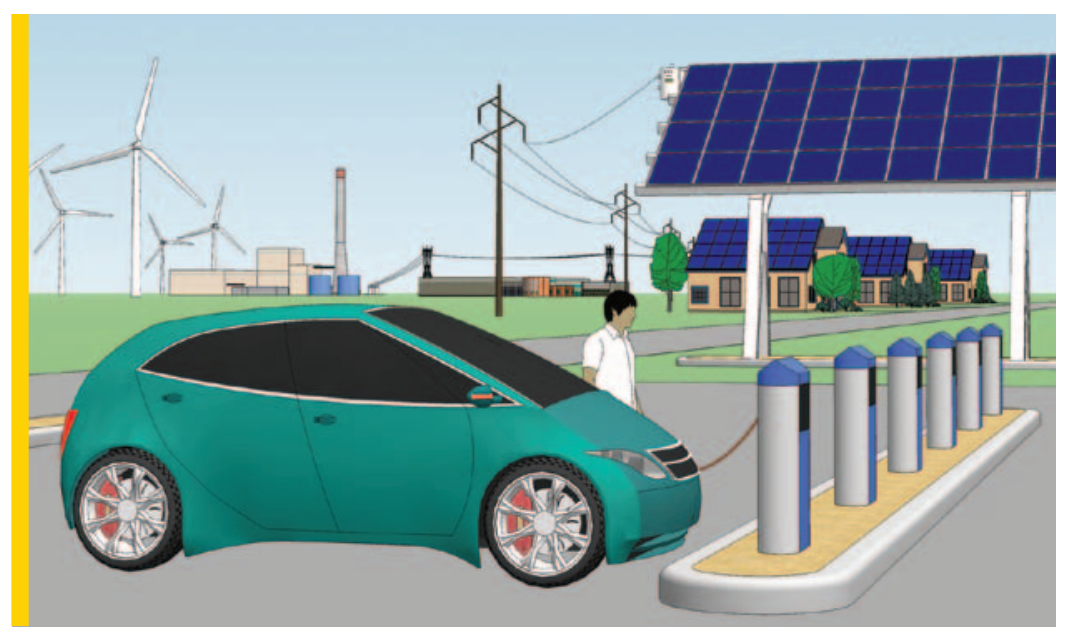

Electric vehicles can reduce fuel use and provide energy storage for renewables such as photovoltaics, helping to balance generation and load requirements.

\subsection{Energy Secure Microgrid Design}

SNL performed a grid security assessment and developed a microgrid design for Fort Carson that would:

- Enhance operational effectiveness while reducing energy demands

- Increase energy resilience by developing alternative/assured fuels/ energy

- Incorporate smart grid architecture and processes to enhance energy assurance

- Balance system safety, security, reliability, cost effectiveness, and sustainability

- Ensure power quality and quantity in evaluated configurations and outage scenarios.

SNL's results describe changes to generation and distribution systems required to implement a secure microgrid at Fort Carson, and provide cost estimates for a range of options.

\section{Contacts:}

Kate Anderson National Renewable Energy Laboratory Sandia National Laboratory kate.anderson@nrel.gov 303-384-7453

\section{5-844-5499}

Mike Warwick

Pacific Northwest National Laboratory mike.warwick@pnl.gov
U.S. DEPARTMENT OF

ENERCY

Energy Efficiency \&

Renewable Energy
For more information contact:

EERE Information Center

1-877-EERE-INFO (1-877-337-3463)

www.eere.energy.gov/informationcenter

Printed with a renewable-source ink on paper containing at least 50\% wastepaper, including $10 \%$ post consumer waste.
Prepared by the National Renewable Energy Laboratory (NREL), a national laboratory of the U.S. Department of Energy, Office of Energy Efficiency and Renewable Energy; NREL is operated by the Alliance for Sustainable Energy, LLC. DOE/GO-102011-3185 • January 2011 